\title{
DEVELOPMENT AND EVALUATION OF POLYHERBAL GEL FOR ANTIFUNGAL ACTIVITY
}

\author{
UMADEVI A. , CHAMPA KUMARI, P. AJITH KUMAR, HAMEEMATH SHAMANA NASMIN AM, DIVYA K., HISANA P. V. \\ Department of Pharmacognosy, Malik Deenar College of Pharmacy, Kasaragod, Kerala, India \\ Email: umanair40@gmail.com \\ Received: 10 Jun 2018, Revised and Accepted: 07 Aug 2018
}

\begin{abstract}
Objective: Piper betal and Piper nigrumare traditional medicinal plants that have antifungal activity against Candida albicans, a combination of these two plants have not been known for its activity against this fungus. The purpose of this research was to formulate topical gel, a combination of $P$. betal and $P$. nigram which has antifungal activity against Candida albicans.

Methods: The antifungal activity test of $P$. betal and $P$. nigrum using agar well diffusion method was carried out. Thereafter, a topical gel formulation was prepared using Sodium carboxymethyl cellulose as a gelling agent of concentration 1; 1.5 and 2\%. Test parameters for topical gel includes organoleptic, $\mathrm{pH}$, extrudability, spreadability, diffusion, and stability test.

Result: The results of this study showed that $P$. betel and $P$. nigrum extracts had antifungal activity. Antifungal activity combination of $P$. betel and $P$. nigrum leaf extract is synergistic. For the formulation materials, the concentration chosen is $1: 1(P$. betel: $P$. nigrum) because in that combination the value of the resistor area is still categorized well. The stability test results stated that all the formulas were stable even after $30 \mathrm{~d}$ of stability studies.

Conclusion: This is the first report on the scientific evaluation of betel and pepper leaf extracts combination as a gel for antifungal activity. Thus our study reveals both leaf extracts to be good antifungals; their methanolic hydro extracts may be formulated as hydrogels with satisfactory
\end{abstract} physicochemical parameters.

Keywords: Piper betal, Piper nigrum, Antifungal activity, Candida albicans, Gel

(c) 2018 The Authors. Published by Innovare Academic Sciences Pvt Ltd. This is an open-access article under the CC BY license (http://creativecommons.org/licenses/by/4.0/) DOI: http://dx.doi.org/10.22159/ijcpr.2018v10i5.29694

\section{INTRODUCTION}

Fungal infection of the skin is now a day's one of the common dermatological problem. There are wide choices for treatment from solid dosage to semisolid dosage form and to liquid dosage formulation. Among the topical formulation, gels have widely accepted in both cosmetics and pharmaceuticals. Within the major group of semisolid preparations, the use of gels has expanded both cosmetics and pharmaceutical preparations [1].

Polyherbal are the formulations containing two or more than two herbs are called polyherbal formulations (PHF). The popularity of polyherbal formulation is due to its high effectiveness towards a number of diseases. Drug formulation in Ayurveda is based on two principles: Use as a single drug and use of more than one drug, in which the latter is known as PHF. This key traditional therapeutic herbal strategy exploits the combining of several medicinal herbs to achieve extra therapeutic effectiveness, usually known as polypharmacy or polyherbalism.

Hydrogels are hydrophilic, polymeric form, capable of absorbing large amounts of water or biological fluids. They are insoluble in water and are available in dry or hydrated sheets or as a hydrated gel in drug delivery systems designed for single use [2-4]. The leaf extract of Piper betel has also been reported to exhibit the biological capabilities of antifungal, anti-cancer, anti-diabetic, anti-ulcer, antifertility. The leaf extract of Piper nigrum is used as an antifungal, anticancer, antidepressant, antidiabetic activities [5, 6].

\section{MATERIALS AND METHODS}

\section{Plant material}

Betel and Pepper leaves were collected from Kasaragod district, Kerala, India. The sample drug has been identified and authenticated from the Department of Botany, Govt College Kasaragod.

\section{Preparation of extract}

The fresh leaves were collected, the drug was air dried in the shade and stored in polythene bags. The dried leaves were powdered mechanically. Powdered leaves were extracted using hydromethanol by maceration method [7].

\section{Preformulation studies}

\section{Incompatibility study}

It is important to detect any possible chemical or physical interactions since they can affect the bioavailability and stability of the drug.

\section{a) Fourier transform infrared spectroscopy}

The compatibility studies were carried out at room temperature using FTIR spectroscopy to determine the drug-drug interaction, drug-excipients/polymer interactions used in the formulation [8].

\section{Preparation of gel}

A weighed quantity of sodium carboxyl methyl cellulose dispersed in $50 \mathrm{ml}$ of distilled water in a beaker with continuous stirring. In $5 \mathrm{ml}$ of distilled water required a quantity of Methyl Paraben and Propyl Paraben dissolved by heating on a water bath. After cooling, it was added to the above mixture. The propylene glycol was added gradually to form a homogenous mass. Selected mixture of drug extract combination (1:1) was added, and volume was made up to $100 \mathrm{ml}$ by adding water. Finally, triethanolamine was added dropwise to the formulation to form a gel of required consistency.

\section{Evaluation}

Following parameters were used for the evaluation of gel

\section{Homogeneity}

All developed gels were tested for visual homogeneity inspection after the gels have been set in the container. They were tested for their appearance.

\section{pH of the gel}

The $\mathrm{pH}$ of the gel was determined by using a digital $\mathrm{pH}$ meter. 


\section{Extrudability}

20 gms of the formulation of gel were each filled in standard collapsible aluminum tubes and sealed by crimping to the end. The weight of the tubes was recorded by weighing. The tubes were placed between two glass slides and were clamped. $500 \mathrm{gm}$ was placed over the slides, and the cap was removed. The amount of the extruded gel was collected, weighed and percentage was calculated.

\section{Spreadability}

The formulation of gels was placed between the 2 glass plates of 5 $\mathrm{cm} \times 2 \mathrm{~cm}$. such that the formulation was sandwiched between the two slides by placing a weight of $100 \mathrm{gm}$ uniformly on the slides. The weight was removed, and the excess of gel was scrapped off. Two slides in a position were fixed to a stand at a $45^{\circ}$ angle without the slightest disturbance so that only the lower slide was held firmly by the clamp, allowing the upper slide to slip off freely with the help of 20 gm weight tied to the upper slide. The time taken for the upper slide to separate away from the lower glass plate was noted. The experiment was done in triplicate, and spreadability was calculated as follows: $\mathrm{S}=\mathrm{W} \times \mathrm{L} / \mathrm{T}$, Where, $\mathrm{S}=$ Spreadability, $\mathrm{L}=$ Length of the glass plate. $\mathrm{W}=$ Weight tied to the upper plate, $\mathrm{T}=$ Time taken $(\mathrm{sec})$.

\section{In vitro diffusion study}

Franz diffusion cell ( $25 \mathrm{ml}$ cell volume) was used for the drug release studies. $1 \mathrm{gm}$ of gel was applied onto the surface of the egg membrane evenly over a fixed area. The receptor chamber was filled with freshly prepared Phosphate Buffer ( $\left.\mathrm{p}^{\mathrm{H}} 5.8\right)$ solution. The receptor chamber was stirred by a magnetic stirrer. The samples (1.0 ml aliquots) were collected at a suitable time interval replaced with fresh buffer solution. Samples were analyzed for drug content by UV visible spectrophotometer at $280 \mathrm{~nm}$ and $342 \mathrm{~nm}$ (eugenol and piperine respectively) after appropriate dilutions. The cumulative amount of drug released across the egg membrane was determined as a function of time $[9,10]$.

\section{Antifungal activity}

Hydro-methanolic leaf extracts of $P$. betel and $P$. nigrum has been incorporated into a gel and studied for its antifungal properties. The fungal culture (Candida albicans) was swabbed over the plate containing Potato dextrose agar media. Different concentration of leaf extract (Piper betel and Piper nigrum 1:1 in Di Methyl Sulphoxide solution) with concentration $(1 \mathrm{mg} / \mathrm{ml})$ and standard $(2 \%$ Ketoconazole) was added to the wells. Then the plate was incubated at room temperature for 2-3 d. The zone of inhibition was measured in $\mathrm{mm}$.

\section{Stability study}

Placebo and the medicated gels were evaluated for their thermostability [12].

\section{RESULTS AND DISCUSSION}

The pre-formulation study was carried out by FTIR method. The results were shown below.

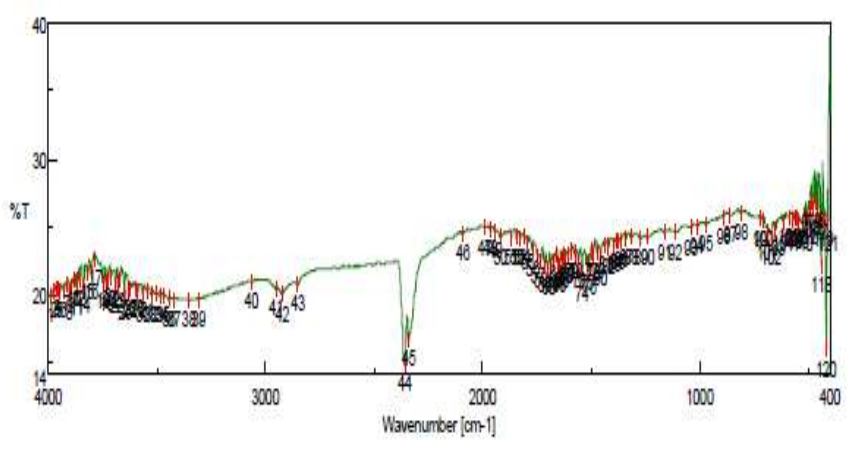

Fig. 1: FTIR (P. betel extract)

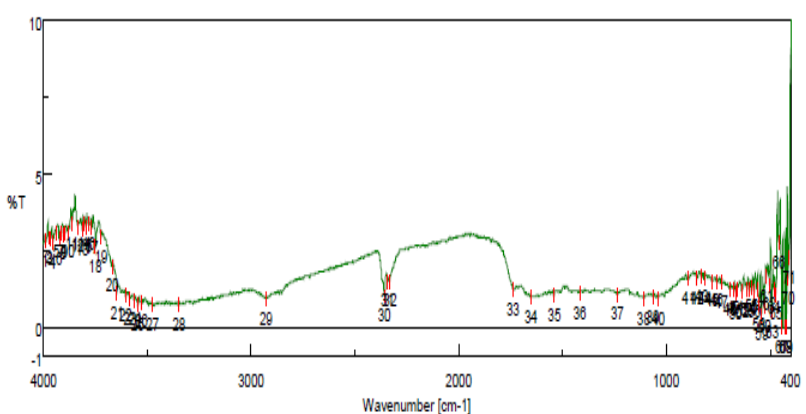

Fig. 2: FTIR (P. nigrum extract)

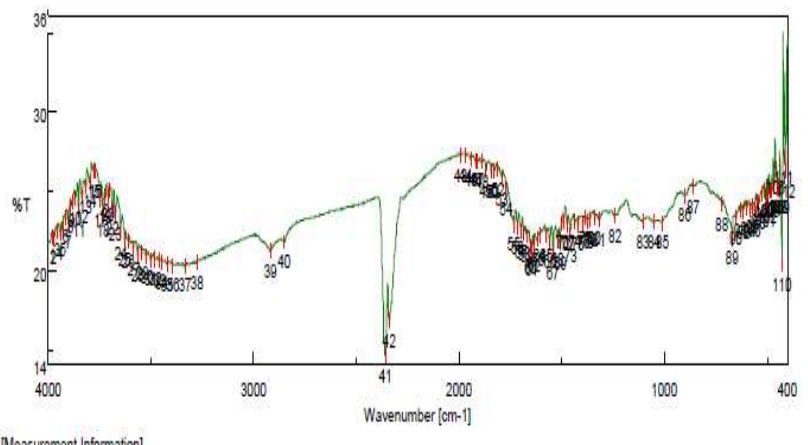

Fig.3: Comparison of the peak of $P$. nigrum and $P$. betel with the physical mixture

Six hydrogel formulations were prepared and evaluated for its physicochemical parameters. It is shown in table 1 and 2 . The in vitro diffusion study was shown in fig. 4 .

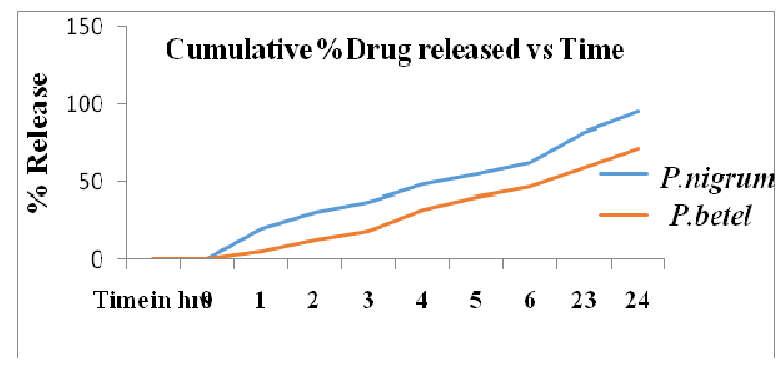

Fig. 4: In vitro drug release of gel with the drug

The formulated gels were tested for antifungal activity. The results were shown in fig. 5, 6 and table 3

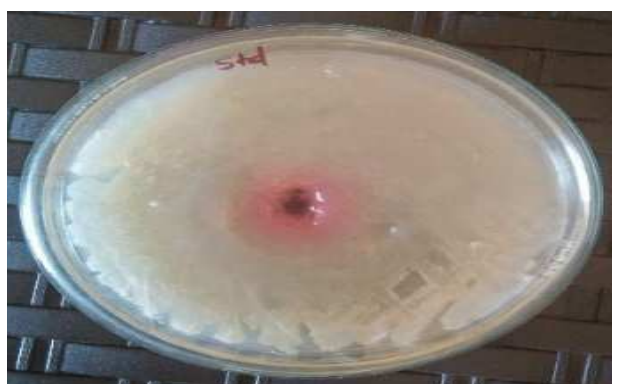

Fig. 5: 2\% Standard (ketoconazole) 
Table 1: Formulation of gel

\begin{tabular}{|c|c|c|c|c|c|c|c|}
\hline S. No. & Ingredients & F1 (\%) & F2 (\%) & F3 (\%) & F4 (\%) & F5 (\%) & F6 (\%) \\
\hline 1 & Extracts of $P$. betel & 10 & 10 & 10 & 10 & 10 & 10 \\
\hline 2 & Extracts of $P$. nigrum & 10 & 10 & 10 & 10 & 10 & 10 \\
\hline 3 & Sodium CMC & 0.25 & 0.5 & 1.0 & 1.5 & 2.0 & 2.5 \\
\hline 4 & Propylene glycol & 5 & 5 & 5 & 5 & 5 & 5 \\
\hline 5 & Triethanolamine & 2 & 2 & 2 & 2 & 2 & 2 \\
\hline 6 & Methyl Paraben & 1 & 1 & 1 & 1 & 1 & 1 \\
\hline 7 & Propyl Paraben & 1 & 1 & 1 & 1 & 1 & 1 \\
\hline 8 & Distilled water (q. s.) & $100 \mathrm{ml}$ & $100 \mathrm{ml}$ & $100 \mathrm{ml}$ & $100 \mathrm{ml}$ & $100 \mathrm{ml}$ & $100 \mathrm{ml}$ \\
\hline
\end{tabular}

Table 2: Data showing physicochemical attributes of combined $P$. betel, $P$. nigrum gels

\begin{tabular}{|c|c|c|c|c|}
\hline Formulation code & Appearance & PH & Extrudability (\%) & Spreadability (g. cm/sec) \\
\hline F1 & +++ & $5.70 \pm 0.06$ & Good & $4.46 \pm 0.56$ \\
\hline F2 & ++ & $5.58 \pm 0.01$ & Excellent & $5.10 \pm 0.42$ \\
\hline F3 & +++ & $5.86 \pm 0.03$ & Excellent & $5.20 \pm 0.35$ \\
\hline F4 & +++ & $6.2 \pm 0.01$ & Excellent & $6.26 \pm 0.55$ \\
\hline F5 & +++ & $5.32 \pm 0.03$ & Good & $5.65 \pm 0.24$ \\
\hline F6 & ++ & $5.63 \pm 0.23$ & Good & $5.80 \pm 0.10$ \\
\hline
\end{tabular}

All values are expressed as mean $\pm \mathrm{SD}++=$ fair,$+++=$ good

Table 3: Evaluation of antifungal activity by agar well diffusion method

\begin{tabular}{lll}
\hline Samples & Zone of inhibition in mm & Fungal culture \\
\hline Leaf extract in combination 1:1 ratio (20\%) & $10 \mathrm{~mm}$ & Candida albicans \\
Leaf extracts as gel-F4 (20\%) & $18 \mathrm{~mm}$ & \\
Ketoconazole (2\%) & $20 \mathrm{~mm}$ & \\
\hline
\end{tabular}
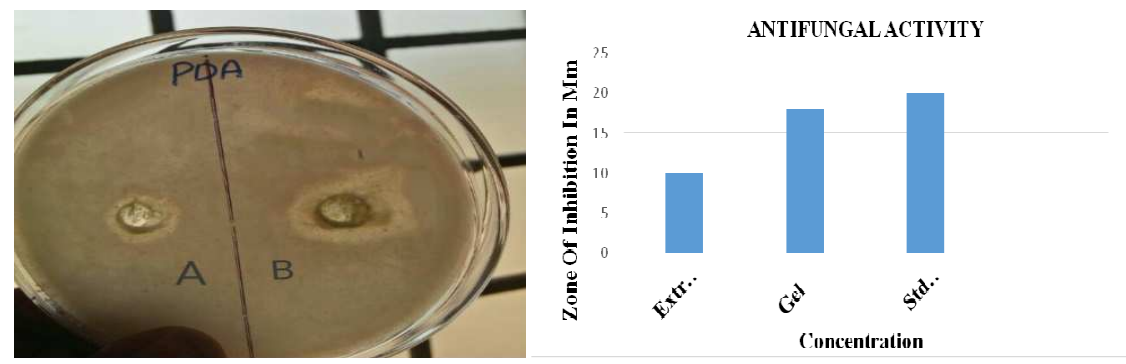

Fig. 6: A-20\% leaf extracts (1:1) B-20\% gel

Table 4: Stability studies

\begin{tabular}{lll}
\hline Formulation & Appearance & Spreadability $($ g. cm/sec) \\
\hline F4 & Homogenous & $6.05 \pm 0.49$ \\
\hline
\end{tabular}

\section{CONCLUSION}

Hydrogel formulation of hydro-methanolic extracts of Betel and pepper leaf combination (1:1) was prepared using sodium carboxymethyl cellulose and gave a gel of satisfactory physicochemical parameters. P. nigrum shows more than $90 \%$ of drug release within $24 \mathrm{~h}$ and $P$. betel shows more than $70 \%$ of drug release within $24 \mathrm{~h}$. Stability studies of the hydro-gel formulations carried out was satisfactory. Study for effects of the formulated gels on candida albicans showed that both drugs either alone or in combination promoted antifungal activity. The antifungal properties of these herbs may be due to their alkaloid, phenol, lignan. Further studies are required to confirm the role of each of these phytoconstituents on antifungal activity. Hence polyherbal formulation/preparations may be better than formulating a single herb. This is the first report on the scientific evaluation of betel and pepper leaf extracts combination as gel for antifungal activity. Thus our study reveals both leaf extracts to be good antifungals; their methanolic hydro extracts may be formulated as hydrogels with satisfactory physicochemical parameters.

\section{ACKNOWLEDGMENT}

We are very thankful to respected principal and management of MalikDeenar College of pharmacy, Kerala for their support

\section{AUTHORS CONTRIBUTIONS}

All the author have contributed equally

\section{CONFLICT OF INTERESTS}

Declared none

\section{REFERENCES}

1. De PV, Mark N, Abel BL. Synthesis and fungicidal, insecticidal activity of new amide derivatives of piperine. Pest Management Sci 2000;56:168-74.

2. Das K, Dang R, Machale M. Formulation and evaluation of a novel gel of stevia extract. Iranian J Dermatol 2009;12:117-22.

3. Gouttum Misra DS, Gopalakrishna Pillai GK. Polyherbal formulation encapsulated in phospholipids for the 
hypoglycemic activity of Momordicacharantia, Trigonellafoenum-graecum, and Withaniasomnifera. J Ethnopharmacol 2017;5:108-547.

4. G Sharmila Banu, G Kumar, AG Murugesan. Antihyperglycemic effect of Garlip, a poliherbal formulation in induced diabetics in rats. Food Chem Toxicol 2009;47:2361-5.

5. Zoheir A Damanhouri, Aftab Ahmad. A review on the therapeutic potential of Piper nigrum L. (Black Pepper): King Spices 2014;3:1-6.

6. Amonkar AJ, Nagabhushan M, D"Souza AV, Bhide SV. Hydroxychavicol: a new phenolic antimutagen from betel leaf. IARC Sci Publications 1991;105:520-4.

7. Madhavi B, Nath AR, Banji D, Madhu MN, Ramalingam R, Swetha D. Extraction, identification, formulation and evaluation of piperine in alginate beads. Int J Pharm Pharm Sci 2009;1:156-8.
8. Ahmad N, Fazal H, Abbasi BH, Farooq S, Ali M. Biological role of Pipernigrum L. (Black pepper): a review. Asian Pacific J Tropical Biomed 2012;2:1945-53.

9. Aiyalu R, Govindarajan A, Ramaswami A. Formulation and evaluation of herbal gel for the treatment of arthritis in an animal model. Brazilian J Pharm Sci 2016;52:493-507.

10. Kaur LP, Garg R, Gupta GD. Development and evaluation of topical gel of minoxidil from different polymer bases in the application of alopecia. Int J Pharm Pharm Sci 2010;2:43-7.

11. Mahmoud DA, Hassanein NM, Youssef KA, Abouzeid MA. Antifungal activity of different Neem leaf extracts and the nimonol against some important human pathogens. Brazilian J 2011;42:1007-16.

12. Velraj M, Soumya D, Sndhukavi D. Antibacterial and antifungal activity of herbal gel from the ethanolic extract of stem bark of Bauhinia variegate Linn. Int J Pharm Sci Rev Res 2016;41:53-6. 